\title{
Exposure of cigarette smoke aggravates noise induced kidney damage
}

\author{
Jamshid Alizadeh $^{1}{ }^{\circledR}$ Zohre Jaffarzadeh $^{1}{ }^{\circledR}$, Kambiz Ahmadi Angali $^{\circledR}$, Massumeh Ahmadizadeh $^{1,3^{*}}$ \\ ${ }^{1}$ Department of Occupational Health, Engineering, School of Health, Ahvaz Jundishapur University of Medical Sciences, Ahvaz, Iran \\ ${ }^{2}$ Department of Statistics and Epidemiology, School of Health, Ahvaz Jundishapur University of Medical Sciences, Ahvaz, Iran \\ ${ }^{3}$ Physiology Research Center, Ahvaz Jundishapur University of Medical Sciences, Ahvaz, Iran
}

\section{AR T I C L E I N F O}

Article Type:

Original

\section{Article History:}

Received: 12 March 2020

Accepted: 10 May 2020

Published online: 30 May 2020

\section{Keywords:}

Noise

Cigarette smoking

GSH

Malondialdehyde

Creatinine

\begin{abstract}
A B S T R A C T
Introduction: Noise is defined as an interfering and unwanted sound. Exposure to noise induces health problems in humans and animals. Cigarette smoke (CS) has also been known to cause serious problems in health hazard and leads to many kinds of diseases. However, the effects of these agents on the kidney are poorly studied.

Objectives: The current study purposes to investigate the impact of noise and/or CS on rat's kidney

Materials and Methods: Four groups of six Wistar adult male rats were used. They randomly were divided into four groups of rats. The first group was used as control. The second group was exposed to noise. The third group was exposed to cigarette smoking and the fourth group was exposed to both noise and CS. The experiments were repeated for two weeks (five days per week). Twenty-four hours after last exposure, the animals were killed by sodium pentobarbital overdose. Renal function was evaluated by the determination of blood urea nitrogen (BUN) and creatinine levels. Oxidative stress was estimated by glutathione (GSH) and malondialdehyde (MDA) assays.

Results: The concentrations of BUN and creatinine remarkably raised $(P \leq 0.05)$ in all groups compared to those in control rats. However, elevations of the biochemical tests were more predominant in rats exposed to combined noise and CS. Elevation of MDA was observed in all exposed rats, while it was more pronounced in the animals exposed to the combined noise and CS when compared to control, CS or noise exposure rats alone. The level of GSH decreased in all exposed groups. It was more obvious in rats exposed to the combined noise and CS when compared to those of control and exposure rats to noise or CS separately.

Conclusion: Exposure to noise or CS impaired renal function. Generation of oxidative stress at least in part may be responsible for their nephrotoxicity. Our findings demonstrated CS aggravated noise induced impairment of renal function.
\end{abstract}

\section{Implication for health policy/practice/research/medical education:}

In this experimental study, we observed, exposing rats to noise or cigarette smoke induced impaired renal function.

Please cite this paper as: Alizadeh J, Jaffarzadeh Z, Ahmadi Angali K, Ahmadizadeh M. Exposure of cigarette smoke aggravates noise induced kidney damage. J Renal Inj Prev. 2021; 10(2): e12. doi: 10.34172/jrip.2021.12.

\section{Introduction}

Noise is described as an unpleasant and unwanted sound. Noise has been associated with numerous health disorders in human and experimental animals. Noise stress is known to be linked to a variety of health problems. It is generally accepted that noise can cause extra-auditory abnormalities such as increased blood pressure; neurological disorders, gastrointestinal motility dysfunction and kidney damage (1-4). Numerous xenobiotics can cause morphological and functional damage to the kidney. Cigarette smoke
(CS) consists of more than 7000 species of substances. In fact, of all environmental pollutions (5). CS is found to be associated with various diseases. Some chemicals of CS are nephrotoxic and can induce adverse effects on renal function. The harmful impact of kidney function was reported previously in mice following short exposure to CS. Raza et al found that tobacco smoke-induced oxidative stress in mice kidney as detected by increasing the levels of reactive oxygen species and the alterations in the metabolism of GSH (6). Additionally, Adedayo et 
al showed, shrinking of the glomerulus and glomerular hemorrhage in rats exposed to tobacco smoke. These authors concluded that exposure of rat to tobacco smoke may be associated with structural damage to the kidney (7). Similarly, Ozan et al demonstrated that CS produced structural alterations in the rat kidney too. The levels of total thiol and tissue proteins were significantly reduced in the kidney of cigarette smoked-exposed rats as compared with control animals (8).

Several studies demonstrated the positive association between smoking and occupational noise exposure. These authors found that inhaling CS will exacerbate hearing loss caused by the noise (9-13). Noise-induced oxidative stress with tobacco smoke which generates free radicals which may lead to serious changes in the kidney. The presence of noise combined with tobacco smoke can be an aggravating factor of the impairment of the kidney. Previously, Sung et al determined that smoking causes accelerate noise evolved hearing loss (10). However, to our knowledge, there is limited data available in the literature regarding their effects on the kidney.

\section{Objectives}

The current study investigated their impact of noise and/ or CS on rat kidney.

\section{Materials and Methods}

\section{Animals}

Twenty-four adult male 200-250 g Wistar rats were provided by maintenance center of laboratory animals Ahvaz Jundishapur University of Medical Sciences. The animals were kept under standard 12/12-hour darkness/ brightness conditions at a temperature of $23 \pm 2{ }^{\circ} \mathrm{C}$ and supplied with food and water ad libitum. They were separated into four groups in a random order (each $n=6$ )

- Group I; control group (These rats did not expose to noise or CS),

- Group II; exposed to $100 \mathrm{~dB}$ noise, 4 hours daily 5 days per week for 2 weeks long,

- Group III; exposed to CS, 4 hours daily 5 days per week for 2 weeks long,

- Group IV; exposed to $100 \mathrm{~dB}$ noise and CS, 4 hours daily 5 days per week for 2 weeks long.

\section{Noise exposure}

The intended noise $(100 \mathrm{~dB}, 700-5700 \mathrm{~Hz})$ was reproduced and recorded in a sound-insulated animal room that was from a large textile factory. During exposure to noise, noise intensity was measured regularly at inside the animal room using calibrated Bruel and Kjaer noise meter device (MODEL 2238). The selected sound intensity was based on previous studies $(14,15)$.

\section{Cigarette smoker exposure}

Animals exposed to CS were kept to a special glass box of
$30 \times 40 \times 60 \mathrm{~cm}$, a hood over the cage to evacuate the extra smoke. The cage had an inlet for the smoking apparatus. The whole body of the rats was exposed to 10 cigarettes for 4 hours daily for 2 weeks ( 5 days per week) (16).

\section{Specimen preparation and measuring}

Twenty-four hours after the last exposure, rats were killed by sodium pentobarbital overdose. Blood has been collected for analyzing renal function, lipid peroxidation, and glutathione levels

\section{Renal function tests}

Renal function was evaluated by the determination of BUN and creatinine levels. The blood urea nitrogen (BUN) was assessed by diacetyl monoxime assay (17), while serum creatinine was done by alkaline Jaffe's picrate method (18).

\section{Peroxidation markers}

The level of blood lipid peroxidation was assessed by determination of malondialdehyde (MDA) as the index for lipid peroxidation. Blood MDA concentration was evaluated by the method of thiobarbituric acid reactive substances (TBARS) (19).

\section{Estimation of plasma level of reduced glutathione}

The blood level of reduced glutathione (GSH) was evaluated by Ellman's method (20).

\section{Ethical issues}

This experimental protocol was performed according to the regulations of the Research Ethics Committee of Iranian Ethical Guidelines for the use of animals in research. Additionally, all animal experiments were in accordance with protocols approved by the United States National Institutes of Health (NIH, 1978). This study was also approved by Ethics Committee of Ahvaz Jundishapur University of Medical Sciences (IR. AJUMS.REC.1394.666). Additionally, This study was extracted from master thesis of Jamshid Alizadeh, at the Occupational Health Engineering Department, School of Health of this university.

\section{Statistical analysis}

Data were expressed as mean \pm standard error. The results were analyzed using SPSS 16.0. The statistical significance between groups is determined by using a one-way analysis of variance (ANOVA), followed by post hoc analysis with least significant difference (LSD) test. Probability value of $\leq 0.05$ was determined to be statistically significant.

Results

\section{Renal function test}

The levels of BUN and creatinine significantly increased $(P \leq 0.05)$ in rats exposed to noise, CS and combined to 
noise and CS as compared to control rats. However, the elevation of the biochemical tests was more predominant in the group exposed to combine noise and CS compared to those in animals exposed to CS or noise only (Figures 1 and 2).

\section{Oxidative stress tests}

Elevation of MDA as the index for lipid peroxidation was observed in all exposed rats in comparison to those in the control group $(P \leq 0.05)$. However, it was more pronounced in the animals exposed to combine noise and CS as compared to those in animals exposed to CS or noise only (Figure 3).

In contrast, the concentration of GSH decreased in all exposed groups in comparison to control rats $(P \leq 0.05)$. However it was more obvious in rats exposed to combine noise and CS when compared to those in the animals exposed to noise or CS only (Figure 4).

\section{Discussion}

Noise is one of the most common harmful agents inducing kidney injury. Our findings demonstrated that the level

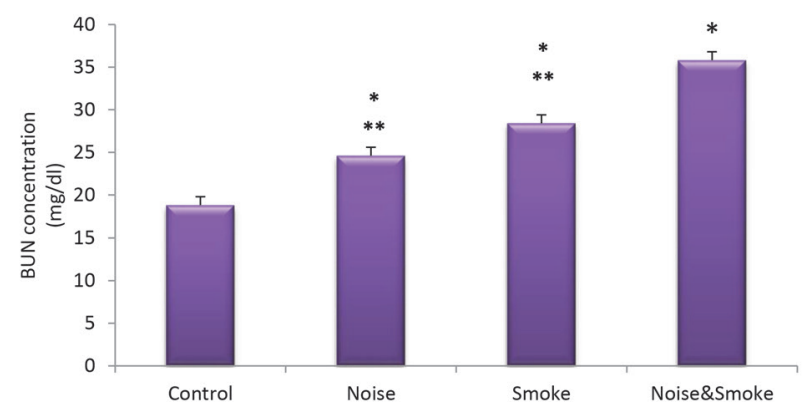

Figure 1. Effect of noise and/or cigarette smoke on BUN level in rats. Each value represents mean \pm SE. of six animals. * Significantly different from control rats $(P \leq 0.05)$. ** Significant difference between animals exposed to combined noise and cigarette smoke $(P \leq 0.05)$.

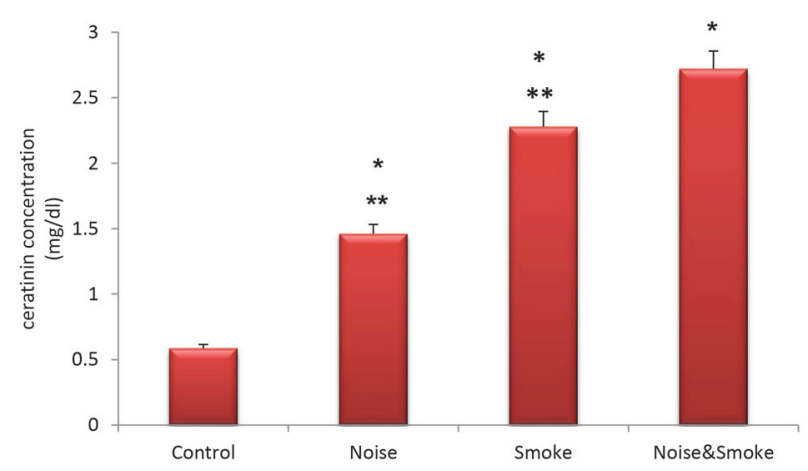

Figure 2. Effect of noise and/or cigarette smoke (smoke) on serum creatinine level in rats. Each value represents the mean \pm SE. of six animals. *Significantly different from control rats $(P \leq 0.05)$. * Significantly difference between animals exposed to combined noise and cigarette smoke $(P \leq 0.05)$. of BUN and creatinine increased in the kidney of rats exposed to noise compared to those in non-exposed rats. Helal et al reported that the levels of BUN and creatinine increased in female rats exposed to noise when compared with control animals. These authors also found that noise caused histopathological damage in mice kidney (3). Similarly, Zymantiene et al demonstrated the biochemical and histopathological alterations in the kidney of female rats exposed to noise (21). Our findings along with others support the view that noise impaired renal function.

The mechanism by which noise produced kidney damage is not fully understood. However, it has been reported that acute and chronic exposure to noise-induced oxidative stress and causes disorder involving an extra-auditory system (22-24). Among them, the kidney is appeared to be relatively susceptible to free radical damage. We observed noise increased the level of malondialdehyde as indicated by lipid peroxidation in rats' sera when compared to unexposed rats. Similarly, Dereköy et al showed the MDA

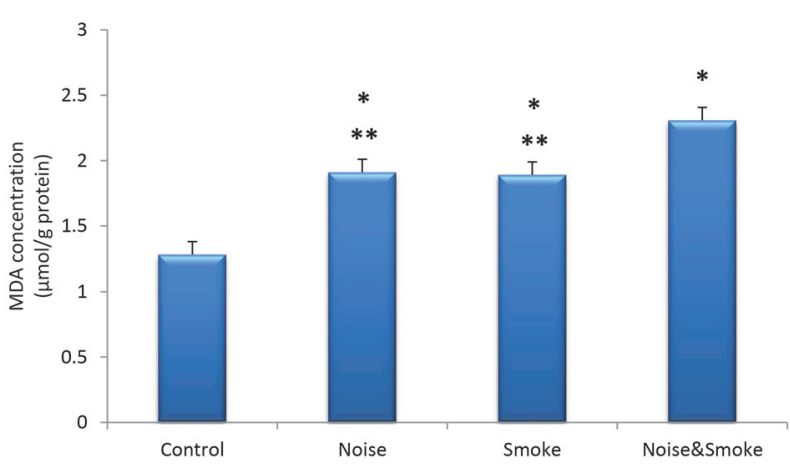

Figure 3. Effect of noise and/or cigarette smoke on malondialdehyde (MDA) level in rats. Each value represents mean \pm SE. of six animals. *Significantly difference in comparison to those in control animals $(P \leq 0.05)$. ** Significantly difference among animals exposed to combine noise and cigarette smoke $(P \leq 0.05)$.

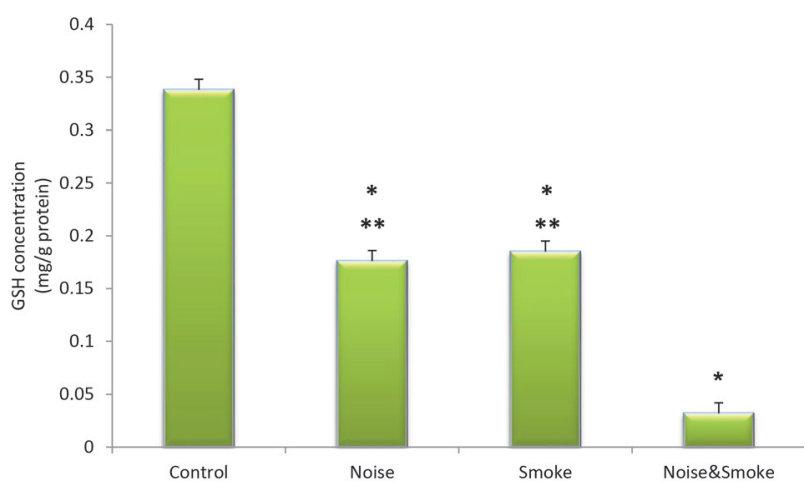

Figure 4. Effect of noise and/or cigarette smoke on glutathione (GSH) level in rats. Each value represents mean \pm SE of six animals. *Significantly difference in comparison to those in control animals $(P \leq 0.05) .{ }^{* *}$ Significantly difference among animals exposed to combine noise and cigarette smoke $(P \leq 0.05)$. 
level enhanced in rabbits following exposure to a $100 \mathrm{~dB}$ sound pressure level (22). Yildirim et al observed higher MDA levels in textile workers when compared to those in control workers (23). Glutathione (GSH) plays a major role in protecting cells against oxidative-induced damage. We found the GSH level decreased in rats exposed to noise compared to unexposed animals. The reduction of GSH value in the sera following exposure of rats to noise was also reported by Koc et al. They showed, noise exposure leads to oxidative stress in rats' serum (24).

Many chemicals induced morphological and functional damage in kidney tissue. The presence of these chemicals and noise may cause the aggravating factor of the impairment of the kidney. Several studies have shown smoking has a higher risk chance in higher frequency hearing loss (9-13). However, most studies have focused on the effects of CS on noise-induced hearing impairment. To our knowledge, very limited study has been focused on the combined effect of these agents on the kidney. Besides noise, exposure to CS also caused impairment of renal function as evaluated by increasing levels of BUN and creatinine when compared to unexposed rats. Pekmez et al reported that CS enhanced BUN level and structural and functional alterations in rats' kidney when exposed to CS (25). Likewise, Suriyaprom et al found the level of BUN was significantly higher in smokers than nonsmokers among males in Bangkok, Thailand who voluntarily participate in the study (26). We observed the level of MDA increased and GSH content decreased in rats sera exposed to CS. These findings support the view that CS could produce kidney damage, by bioactivation of reactive toxic metabolites and generation of oxidative stress.

We also observed that presence of the noise with CS caused potentially more damage to the kidney than when each insult separately. The levels of BUN, serum creatinine and MDA considerably higher since the level of GSH significantly lower in rats exposed to combined noise and CS in comparison to those in the animals only exposed to noise or CS. These findings suggest that kidney injury is more pronounced in rats exposed to CS and noise than those observed in animals exposed to noise only. Solvents and metals are considered a risk factor associated with noise. The presence of noise combined with some of this nephrotoxic agent can be potentially more harmful than when exposed separately. Cobanoglu et al, reported histopathological damage in the kidney was more pronounced in rats exposed to CS and thinner in comparison to only thinner exposed animals (27). The histological changes in the kidney of CS and ethanol were also more severe than those observed in CS alone (28).

\section{Conclusion}

Noise and CS impaired kidney function. The mechanism by which this agents-induced nephrotoxicity appears to be due to at least in part to the generation of oxidative stress.
However, CS aggravated the noise-induced impairment kidney function

\section{Acknowledgments}

The authors wish to thank the research deputy of Ahvaz Jundishapur University of Medical Sciences for offering the grants for this investigation. The source of data used in this paper was from the master thesis of Jamshid Alizadeh, student of Occupational Health Engineering Department, School of Health, Ahvaz Jundishapur University of Medical Sciences, Ahvaz, Iran.

\section{Authors' contribution}

JA provided technical assistance, collection, and preparation of the manuscript. KA analyzed the data. MA designed, supervised the study and prepared the final draft of the article.

\section{Conflicts of interest}

The authors declared no competing interests.

\section{Ethical considerations}

Ethical issues (including plagiarism, data fabrication, double publication) have been completely observed by the authors.

\section{Funding/Support}

This study was supported by the Physiology Research Center and the research deputy of Ahvaz Jundishapur University of Medical Sciences (Grant \#APRC-9501).

\section{References}

1. Stansfeld SA, Matheson MP. Noise pollution: non-auditory effects on health. Br Med Bull. 2003;68:243-57. doi: 10.1093/ bmb/ldg033

2. Belojević G, Paunović K. Recent advances in research on non-auditory effects of community noise. Srp Arh Celok Lek. 2016;144:94-8. doi: 10.2298/SARH1602094B

3. Helal EG, Eid F, Taha NM. Protective effects of sulpiride treatment on kidney functions of female albino rats exposed to noise stress. Eygp Hosp Med. 2011;44:284-94. doi: $\quad$ 10.12816/EJHM.2011.16408

4. Zhang L, Ji T, Gong JT, Hu Q, Zhang HQ, Quan H, et al. Melatonin Attenuates Noise Stress-induced gastrointestinal motility disorder and gastric stress ulcer: role of gastrointestinal hormones and oxidative stress in rats. J Neurogastroenterol Motil. 2015;21(2):189-99. doi: 10.5056/ jnm14119.

5. Rodgman A, Perfetti T. The chemical components of tobacco and tobacco smoke. Boca Raton, FL: CRC Press; 2009. pp. 1483-784.

6. Raza H, John A, Nemmar A. Short-term effects of noseonly cigarette smoke exposure on glutathione redox homeostasis, cytochrome $\mathrm{P} 4501 \mathrm{~A} 1 / 2$ and respiratory enzyme activities in mice tissues. Cell Physiol Biochem. 2013;31:683-92. doi: 10.1159/000350087.

7. Adedayo AD, Tijani AA, Musa AA, Adeniyi TD. Histological 
study of smoke extract of Tobacco nicotiana on the heart, liver, lungs, kidney, and testes of male Sprague-Dawley rats. Niger Med J. 2011;52:217-22. doi: 10.4103/03001652.93791.

8. Ozan E, Sonmez MF, Ozan S, Colakoglu N, Yilmaz S, Kuloglu T. Effects of melatonin and vitamin C on cigarette smoke-induced damage in the kidney. Toxicol Ind Health. 2007;23:479-85. doi:10.1177/0748233708089023

9. Tao L, Davis R, Heyer N, Yang Q, Qiu W, Zhu L, et al. Effect of cigarette smoking on noise-induced hearing loss in workers exposed to occupational noise in China. Noise Health. 2013;15:67-72. doi: 10.4103/1463-1741.107159.

10. Sung JH, Sim CS, Lee CR, Yoo CI, Lee H, Kim Y, Lee J. Relationship of cigarette smoking and hearing loss in workers exposed to occupational noise. Ann Occup Environ Med. 2013;25:8. doi: 10.1186/2052-4374-25-8

11. Habybabady RH, Mohammadi M, Mortazavi SB, Khavanin A, Mirzaei R, Malvajerdi MS. The effect of simultaneous exposure to cigarette smoke and noise on distortion product otoacoustic emissions in rats. Toxicol Ind Health. 2019;35:349-57. doi: 10.1177/0748233719839865.

12. Ferrite S, Santana V. Joint effects of smoking, noise exposure and age on hearing loss. Occup Med (Lond) 2005;55:48-53. doi: 10.1093/occmed/kqi002.

13. Mizoue T, Miyamoto T, Shimizu T. Combined effect of smoking and occupational exposure to noise on hearing loss in steel factory workers. Occup Environ Med. 2003;60:56-9. doi: 10.1136/oem.60.1.56.

14. Oliveira M, Freitas D, Carvalho A, Guimarães L, Pinto A, Águas A. Exposure to industrial wideband noise increases connective tissue in the rat liver. Noise Health. 2012;14:2279. doi: 10.4103/1463-1741.102959 .

15. Samson J, Sheeladevi R, Ravindran R, Senthilvelan M. Stress response in rat brain after different durations of noise exposure. Neurosci Res. 2007;57:143-7. doi: 10.1016/j. neures.2006.09.019.

16. Abdul-Ghani R, Qazzaz M, Dabdoub N, Muhammad $\mathrm{R}$, Abdul-Ghani A. Studies on cigarette smoke induced oxidative DNA damage and reduced spermatogenesis in rats. J Enviro Biol. 2014;35:943-47.

17. Rosenthal HL. Determination of urea in blood and urine with diacetyl monoxime. Anal Chem. 1955;27:1980-82. doi: 10.1021/ac60108a039.

18. Owen A, Iggo B, Scandrett FJ, Stewart CP. The determination of creatinine in plasma or serum and in urine: a criticalexamination. Biochem J. 1954;58:426-37.

19. Buege JA, Aust SD. Microsomal lipid peroxidation. Methods Enzymol. 1978;52:302-10. doi:10.1016/s00766879(78)52032-6.

20. Ellman GL. Tissue sulfhydryl groups. Arch Biochem Biophys. 1959;82:70-7. doi: 10.1016/0003-9861(59)900906.

21. Zymantiene J, Zelvyte R, Pampariene I, Aniuliene A, Juodziukyniene N, Kantautaite J, et al. Effects of long-term construction noise on health of adult female Wistar rats. Pol J Vet Sci. 2017;20:155-165. doi: 10.1515/pjvs-2017-0020.

22. Dereköy FS, Köken T, Yilmaz D, Kahraman A, Altuntaş A. Effects of ascorbic acid on oxidative system and transient evoked otoacoustic emissions in rabbits exposed to noise. Laryngoscope. 2004;114:1775-9. doi: 10.1097/00005537200410000-00019.

23. Yildirim I, Kilinc M, Okur E, Inanc Tolun F, Kilic A, Kurutas $\mathrm{EB}$, et al. The effects of noise on hearing and oxidative stress in textile workers. Ind Health. 2007;45:743-9. doi: 10.2486/ indhealth.45.743.

24. Koc ER, Ersoy A, Ilhan A, Erken HA, Sahın S. Is rosuvastatin protective against on noise-induced oxidative stress in rat serum? Noise Health. 2015;17:11-6. doi: 10.4103/14631741.149565.

25. Pekmez H, Ogeturk M, Ozyurt H, Sonmez MF, Colakoglu $\mathrm{N}$, Kus I. Ameliorative effect of caffeic acid phenethyl ester on histopathological and biochemical changes induced by cigarette smoke in rat kidney.Toxicol Ind Health. 2010;26:175-82. doi: 10.1177/0748233710362380.

26. Suriyaprom K, Harnroongroj T, Namjuntra P, Chantaranipapong Y, Tungtrongchitr R. Effects of tobacco smoking on alpha-2-macroglobulin and some biochemical parameters in Thai males Southeast Asian J Trop Med Public Health. 2007;38:918-26.

27. Cobanoglu B, Ozercan IH, Ozercan MR, Yalcin O. The effect of inhaling thinner and/or cigarette smoke on rat kidneys. Inhal Toxicol. 2007;19:303-8. doi: 10.1080/08958370601141890.

28. Cigremis Y, Turkoz Y, Tuzcu M, Ozen H, Kart A, Gaffaroglu $\mathrm{M}$, et al. The effects of chronic exposure to ethanol and cigarette smoke on the formation of peroxynitrite, level of nitric oxide, xanthine oxidase and myeloperoxidase activities. Mol Cell Biochem. 2006;291:127-38. doi: 10.1007/ s11010-006-9205-8.

Copyright $\odot 2021$ The Author(s); Published by Nickan Research Institute. This is an open-access article distributed under the terms of the Creative Commons Attribution License (http://creativecommons.org/licenses/by/4.0), which permits unrestricted use, distribution, and reproduction in any medium, provided the original work is properly cited. 